\title{
Factors Associated with Desistance from Violence in Prison: An Exploratory Study
}

\author{
Sophie Ellis ${ }^{a}$ and Erica Bowen ${ }^{b}$ \\ School of Health and Life Sciences, Coventry University, Priory Street, Coventry, \\ $C V 15 F B$
}

In press in Psychology, Crime \& Law

\footnotetext{
${ }^{a}$ New affiliation: Forensic Psychologist in Training, The East Psychology Services, National Offender Management Service. HMP Wayland, Griston, Thetford, Norfolk, IP25 6RL.01953 804074.sophie.ellis@hmps.gsi.gov.uk

${ }^{b}$ New affiliation: Professor of Violence Prevention Research, National Centre for the Study and Prevention of Violence and Abuse (NCSPVA). Institute of Health and Society, University of Worcester (BB199), Henwick Grove, Worcester, WR2 6AJ. 01905 542611.E.Bowen@worc.ac.uk
} 


\begin{abstract}
Desistance from crime has been of increasing interest within criminal justice literature, but desistance from offending behaviour whilst in custodial environments has not yet been investigated. Violence within prison establishments continues to be a significant problem, therefore this study investigated the factors that are associated with desistance from custodial violence in 63 UK Category $\mathrm{C}$ adult male prisoners with a record of violence in prison. Participants completed measures of eight social and subjective factors associated with desistance in community samples. Those who had desisted from prison violence for 12 months or more showed greater levels of pro-social attitudes, agency and resilience than those who persisted in violence. Agency independently predicted desistance and this was particularly the case for younger offenders. Internal shifts appeared to be supported by a positive work environment. It is concluded that in custody an internal shift in perspective is especially important for desistance, and that this can be supported by the social environment. Opportunities to intervene may be greater in younger prisoners. It is recommended that current initiatives in developing agency and positive social interaction, such as Psychologically Informed Planned Environments, are further developed.
\end{abstract}

Keywords: desistance; prison violence; problem behaviours; protective factors; criminal careers

\title{
Introduction
}

Prison violence is a costly and harmful problem. Within the UK, 22,195 assaults occurred in the 12 months prior to March 2016; a 31\% increase on the previous year (Ministry of Justice, 2016). These figures have followed a period of relative stability in violence rates, indicating that the problem may stem from recent factors. In 2011$12, £ 157$ million was cut from the Prison Service budget, with further cuts of $£ 450$ million planned over the next six years (National Offender Management Service [NOMS], 2013). A cross-party investigation into the impact of these cuts raised concerns about rises in assaults and reduction in staff numbers (House of Commons 
Committee of Public Accounts, 2013), indicating that violence may continue to rise in the future alongside further cuts, unless more is done to tackle the problem.

Current custodial practices for reducing violence target individual and situational violence risk factors (NOMS, 2012). Conversely, community practices are beginning to target factors that lead to desistance from violence in the continued presence of risk. Desistance refers to the established trend for most offenders to stop offending eventually, with the exact trajectory determined by the mix of risk and protective factors that are present. An explicitly desistance-based violence reduction approach has not yet been applied to incarcerated samples. Homel and Thompson (2005) point out that 'the wonder is that there is not more violence in prisons' (p. 1) given that they house anti-social individuals together in restricted conditions. Consequently, identifying the factors that contribute to desistance is an avenue worthy of further exploration. It is possible that it may be more cost-effective to enhance protective factors associated with desistance from violence in custody.

The desistance literature comprises two distinct schools of thought which have, to an extent, become combined. Laub and Sampson (1993) proposed social control theory which states that individuals desist when they develop social bonds to conventional society, mainly a job and a spouse. McNeill and Weaver (2015) also emphasised the influence of social relations on desistance; specifically how such relations either facilitate or inhibit different behaviours. In contrast Giordano, Cernkovich and Rudolph (2002) and Maruna (2001) emphasised the importance of subjective cognitive shifts inside the offender which motivate them to seek out prosocial bonds and respond positively to any opportunities offered to access these. Such shifts may include a change in attitude where crime becomes seen as unacceptable, an increased perception of personal choice, enthusiastic adoption of a reformed, pro-social identity and overinflated optimism in being able to overcome difficulties. Recent researchers have proposed that social and subjective factors interact bi-directionally in order for desistance to occur. For example, Bottoms et al. (2004) conclude from their longitudinal study of 113 young adult male offenders that the level of social capital available as compared to obstacles to desistance faced, is an important influence. However, it appears to be an individual's disposition that determines whether obstacles are met with reoffending or continued desistance. Within their sample of 101 probationers, Farrall and Calverley (2006) found that those with a "confident" outlook were more likely to continue to desist in the 
presence of obstacles compared to those with a "pessimistc" outlook, for whom obstacles were more likely to interfere with maintaining desistance. Similarly, LeBel, Burnett, Maruna and Bushway (2008) concluded in their study of 130 adult male property offenders that a 'subjective-social' model of desistance was a best fit for their data. They found that subjective factors such as self-identification as a 'family man' and self-efficacy were marginally predictive of desistance, as long as social problems (e.g. unemployment) were not too excessive, suggesting that these subjective factors help offenders to take advantage of social opportunities but only if they are present. Overall the most recent evidence suggests that both social and subjective factors are important in the desistance process, with the way in which they interact determining the trajectory. There is also a growing consensus that desistance should be conceptualised as a process rather than an event. For example Farrall and Calverley (2006) discuss the process of "primary" desistance, which can be a temporary crime free lull, prior to permanent "secondary" desistance, which involves a fundamental internal shift towards an identity incompatible with offending.

The specific factors shown to influence desistance from community violence in the face of continued risk may also be relevant to ceasing violence in other risky environments, such as prison. Conversely, these factors may have differential effects (or no effects) due to the unique characteristics of prison. In the present study, four social factors and four subjective factors are examined within a custodial sample of persisters and desisters in prison violence. These factors were selected because they have already been widely researched within community samples and there is evidence to suggest that they are associated with community desistance.

\section{Social factors}

\section{Employment}

Some studies have found a positive relationship between employment and desistance (Sampson and Laub, 2003; Stouthamer-Loeber et al., 2004; Uggen, 2000) and others have found none (Giordano et al., 2002; Haggard, Gumpert and Grann, 2001; Rhodes, 1989), suggesting a complex relationship. Sampson and Laub (2003) theorise that employment is linked to desistance because it disrupts routine criminal activities and anti-social peer networks. If this explanation is correct, then employment could be expected to have less effect on desistance from prison violence 
as opportunities remain for violent behaviour within prison workplaces, as do antisocial peers. Similarly, McNeill and Weaver (2015) concluded that it is the social context of employment, rather than employment itself which influences the choice to desist. Therefore according to this explanation, continued anti-social peer presence would ameliorate the effect of employment. However, some studies have already found that engaging in 'purposeful activity' in prison reduces staff-prisoner assaults (McCorkle, Miethe and Drass, 1995; Walrath, 2001), suggesting employment can exert an effect in prison. Crewe, Warr, Bennett and Smith (2014) investigated the "emotional geography" of prisons and concluded that pro-social interaction and vulnerable emotional expression varied by location, with prison workshops seen as areas where emotional expression is less permissible, compared to other areas of employment such as education, visits and the chapel. Therefore, employment may only influence desistance from prison violence if it is in a place of positive social relations and is perceived as purposeful.

\section{Stable intimate relationship}

Research has identified a positive relationship between desistance and a stable intimate relationship (Bottoms and Shapland, 2011; Farrington and West, 1995; Haggard et al., 2001; Horney, Osgood and Marshall, 1995; Laub, Nagin and Sampson, 1998). Stronger attachment exerted a greater effect in those studies which measured the quality of an intimate relationship as well as presence. Sampson and Laub (2003) and McNeill and Weaver (2015) argued that an intimate relationship is effective because it is an important source of social control and accountability. As it is not possible to sustain a close relationship from prison in the same way as in the community, these mechanisms are likely to be less effective. Alternatively it may be that the presence of a relationship feeds into a prisoner's identity as a "family man", which has been linked with desistance (LeBel et al., 2008 and Maruna 2001) and may be maintained in custody despite the physical absence of their spouse/partner.

\section{Community bonds}

A positive relationship has been found between desistance and bonds to community structures, such as family, school and religious centres (Haggard et al., 2001; LeBel et al., 2008; Ullrich and Coid, 2011; McNeill and Weaver 2015). However, it could 
be argued that community bonds will have the opposite effect in prison as bonds to other prisoners could reinforce shared pro-violent attitudes found within prison communities (Cheliotis, 2014; Toch, 1998). However, Crewe et al. (2014)'s concept of emotional geography suggests that feeling bonded to prison institutions where such attitudes are not reinforced (e.g. religious centres) may be important in the process of desistance from prison violence.

\section{Pro-social support}

Various studies have found a positive relationship between pro-social support and desistance. These include support from pro-social co-workers (Wright and Cullen, 2004), pro-social partners (MacDonald, Webster, Shildrick and Simpson, 2011) and pro-social peers (Chung et al., 2002; Fergusson, Lynskey and Horwood, 1996; van Domburgh et al., 2009; Warr, 1993). Prisoners are restricted in choosing their associates. It may therefore be that pro-social support is important but may not exert as strong an effect as in the community, particularly if pro-social relationships are experienced as an isolated incident amongst a broader anti-social culture, as Crewe et al. (2014)'s work suggests is the case.

\section{Subjective factors}

\section{Pro-social attitudes}

Pro-social attitudes are associated with desistance (Hawkins et al., 1998; Herrenkohl et al., 2001; Herrenkohl et al., 2003 Loeber et al., 1998). Giordano et al. (2002) and Maruna (2001) found that in order for desistance to occur, attitudes needed to change such that crime was viewed as unacceptable, not relevant and not valuable. It therefore follows that if prisoners develop such a view of violence then desistance may also occur. However, it may be that prisoners' attitudes do not necessarily translate so readily to their behavior within prison, due to the pressures of the environment to demonstrate a "tough" form of masculinity (Crewe et al. 2014). 
Personal agency and control over the choice of whether to offend in the future, with a strong belief that it is possible to desist has repeatedly emerged as important in the desistance process (Bottoms and Shapland, 2011; Burnett, 2004; Farrall and Caverley, 2006; LeBel et al., 2008; Serin and Lloyd 2009; MacDonald et al., 2011; Maruna, 2001; Shover, 1996). It could be argued that the role of agency will not be any different in a prison environment, as prisoners high in agency will exercise choice in the face of opportunities for violence and obstacles to desistance, as they would in the community. However, the very nature of the prison environment restricts choice and autonomy. Crewe et al. (2014)'s work suggests that prisoners will deliberately adopt different identities within different custodial contexts. Hence whilst a sense of personal agency may be high, situational factors may mean that this translates to a choice to maintain a violent identity under certain conditions and a non-violent identity under others. The evidence therefore suggests that agency will exert some effect on desistance in prison but may work more effectively under certain conditions.

\section{Resilience}

Another subjective factor that is emerging as important in the desistance process is personal resilience. Rennie and Dolan (2010) and Werner and Smith (1992) found that resilience alone can function as a protective factor in the presence of risk factors, indicating that it may be a particularly important quality for desisters. This is supported by Farrall and Calverley (2006)'s finding about more successful desistance in confident probationers compared to pessimistic ones. These findings suggest that resilience may be particularly important for desistance in a prison environment where obstacles and risk factors will continue to be present.

Age

Age is not always considered as a subjective factor but here it is classed as such because it represents an internal change. There is evidence that the age at which some social factors are experienced affects the likelihood of desistance. Knight, Osborn and West (1977) found that marriage had no effect on desistance if the offender married under the age of 21. Uggen (2000) found that employment opportunities were more likely to be associated with desistance in offenders aged 
over 26. Shover and Thompson (1992) found that the relationship between age and desistance was mediated by optimism for legitimate success. The evidence therefore seems to suggest that desisters are more likely to be older than persisters, contingent upon whether they also have some of the other factors described. There is nothing to suggest that this would be different within a prison environment, as evidence suggests that prisoners still undergo maturation processes despite having fewer development opportunities (Toch, 2008; Toch, 2010). Therefore age may exert an independent effect and/or interact with other factors.

\section{Aims and hypotheses}

There are two main aims of the present study. First, it will investigate how individuals who persist or desist from using prison violence differ on eight factors that have been associated with desistance from community violence. It is hypothesised that the two groups will differ in their perception of employment as meaningful, strength of attachment within their intimate relationship, bonds to the prison community, level of pro-social support, strength of pro-social attitudes, sense of personal agency, level of resilience and age. No predictions are made about the direction of the differences at this stage as, although evidence does suggest that desisters should score more highly on all factors, some findings suggest that the characteristics of the prison environment means that these factors may exert a weaker or differential influence. It is also hypothesised that age will mediate the relationship between the identified factors and desistance, with greater effects observed in older prisoners. A secondary aim of the study is to determine the relative importance of the identified factors in predicting desistance from prison violence.

\section{Method}

\section{Design}

The study employed a cross-sectional, between-subjects design with data collected via a paper-based self-completion questionnaire. The independent variable was defined as 'violence status', with two levels. These were 'desister' (participants had a record of violence on their current sentence but no proven adjudications for violence in the 12 months prior to the study) and 'persister' (participants had a 
record of violence on their current sentence and at least one proven adjudication for violence in the 12 months prior to the study). Violence was defined as actual, attempted or threatened harm committed in custody and included incidents of physical aggression, verbal aggression, threats, making weapons and firesetting (definition adapted from Douglas, Hart, Webster and Belfrage, 2013). A record of violence was operationalised as 'having a number of proven adjudications for violence greater than or equal to the number of years served'. So for example a prisoner with four adjudications for violence that had served 20 years would not be included in the study. Conversely, a prisoner with four adjudications who had served two years would be included. This definition was chosen so as to only include participants who had persistently engaged in violence for a period of time, and excluded those for whom violence had only been a rare occurrence during their sentence.

The two groups were compared on eight dependent variables which have been associated with desistance in the community: meaningful employment (with 'meaningful' meaning it is perceived as a positive and purposeful experience by the offender), attachment within an intimate relationship, community bonds, pro-social support, pro-social attitudes, sense of agency, resilience and age.

\section{Participants}

Participants were adult male prisoners incarcerated in a Category $\mathrm{C}$ training prison in the UK. The adjudication records of all prisoners $(n=1338)$ were screened in order to identify those who met the criteria described in the Design section. One hundred and thirty-five prisoners were suitable for the study. Forty-one were transferred or released before the data collection period. Five were excluded as they were currently in treatment with one of the authors, and inclusion may have jeopardised informed consent or harmed the therapeutic alliance. This left eighty-nine suitable candidates who were all approached for the study. The response rate was $77.5 \%(n=69)$. Four later withdrew from the study, and two were deemed unable to give informed consent due to mental health issues, leaving a total sample of sixty-three participants. Of these, forty-two were categorised as persisters and twenty-one were categorised as desisters. An a priori power analysis indicated that a sample size of 312 was ideal to fully detect any effects from the eight dependent variables, therefore there is a risk 
that some effects were not detected. The mean age of the sample was twenty-six years and seven months $(\mathrm{SD}=$ six years). The majority of participants $(82.5 \%, \mathrm{n}=$ 52) resided on a standard residential unit. Further demographic data was not collected in order to preserve anonymity; however, prisoners at the establishment are typically serving sentences of between one year and life for a diverse range of offences including violence, but rarely sex offences.

\section{Measures}

Full details of validated samples, reliability coefficients, number of items, scoring method and direction can be found in Appendix I.

\section{Meaningful employment}

The Basic Psychological Needs at Work Scale (Brien et al., 2012) was used to measure perception of employment as meaningful. It has three sub-scales: autonomy, relatedness and competence. Presence or absence of employment was also recorded.

\section{Relationship attachment}

Four items from the National Youth Survey (NYS; described and used in Maume, Ousey and Beaver, 2005) that focus on the quality of marital attachment were used. These were chosen due to their successful use in a large-scale study $(\mathrm{n}=1725)$ and for the fact that it is a relatively short yet reliable measure (Maume et al., 2005). The scale involves rating martial warmth, support, stress and satisfaction. The scale was adapted to refer to 'stable, long-term relationships' rather than 'marriage'. This ensured that the quality of relationship remained the target variable, regardless of whether the participant is married to their partner. Presence or absence of an intimate relationship was also recorded.

\section{Community bonds}

The extent of community bonds was measured using the Perceived Community Support Questionnaire (Herero and Gracia, 2007). This measures the extent to which 
people feel integrated with and supported by their community. It consists of three subscales: community integration, community participation and use of community organisations, however only the overall score was used as two of the three sub scales did not have adequate internal reliability when piloted. The wording of the questions refers to 'my community'. In the instructions, participants were prompted to answer the questions in relation to their membership of the prison community.

\section{Pro-social support}

The Perceived Attributional Support Questionnaire (Clinkinbeard and Murray, 2012) was used as inspiration for an original measure more suitable for this study. Participants were asked to list up to ten people in their support network and rate those people's views on violence (violence is never, rarely, sometimes, mostly or always justified).

\section{Pro-social attitudes}

The extent to which participants held pro-social attitudes was measured by Crime PICS II (Frude, Honess and Maguire, 2013). This is an inventory that measures general attitudes to offending. It includes scales of 1) general attitude to offending, 2) evaluation of crime as worthwhile, 3) victim hurt denial and 4) anticipation of reoffending. Only the first scale was used as the second and third did not have adequate internal reliability when piloted and the fourth overlaps with the separate agency measure.

Agency

This was measured using the Agency for Desistance Questionnaire (Lloyd and Serin, 2012). This measures the psychological aspects of desistance, including intention to change, perceived ability to change and expectancy of change. It is a unidimensional measure.

\section{Resilience}


This was measured using the ten item version of the Connor-Davidson Resilience Scale (Campbell-Sills and Stein, 2007). It is a unidimensional measure.

\section{Procedures}

Those identified as suitable for the study were sent an information sheet describing the study and a letter stating the date that questionnaires would be given out on their particular residential unit. Potential participants were approached when returning from work to their residential unit (or earlier if they were unemployed) and asked if they wished to take part. Exceptions were suitable prisoners currently receiving support for suicidal behavior, self-harm and mental distress and suitable prisoners currently located in the Segregation unit on the day of data collection. If those approached agreed, informed consent was gained. Participants who appeared mentally unwell or under the influence of illicit substances were not considered able to give informed consent. It was emphasised to all potential participants that there were no rewards or punishments associated with their choice.

Participants who agreed to take part were given a questionnaire booklet to complete over lunchtime when locked in their cells. The booklet contained complete written instructions. In order to maintain anonymity the booklets were only marked with a code number indicating whether it was completed by a persister or desister. Participants who had low levels of literacy were identified prior to being approached, and were offered the option of having questions read out loud by the researcher at another time. Two participants chose this option. Upon completion of the booklet, participants were given a debrief pack, containing a written debrief and information about further support available. The pack contained an addressed envelope with the participant's code number, which they were instructed to return within two weeks if they wished to withdraw from the study.

\section{Pilot study}

Ten prisoners completing education and offending behaviour courses were used for the pilot study, as they were conveniently accessible. They were excluded from the main study. The first pilot showed satisfactory internal reliability for all measures except the relationship attachment measure, two of the CRIME-PICS II subscales 
and the agency measure. These problems could be partially attributed to only five participants being in a relationship and only items at the extreme ends of the agency scale being used. Participants also found the pro-social support measure to understand. A second pilot with seven additional participants, clearer instructions for the agency measure and a revised pro-social support measure resolved the majority of issues. The two problematic subscales of CRIME-PICS II were removed.

\section{Results}

Data were screened for normality, which was satisfactory for all measures. Missing data were replaced with mean values where less than $10 \%$ of the item scores for a scale were missing, due to the small amount missing data overall.

[Table 1 about here]

\section{Social factors}

Table 1 shows the correlation matrix between the continuous dependent variables. The total score for meaningful employment was strongly correlated with each of the meaningful employment subscales ( $\mathrm{r}=.8$ and above in all cases) and did not add anything uniquely meaningful to the analysis. From this point only the subscale total scores are used. The autonomy sub-scale showed a weak positive relationship with relationship attachment $(\mathrm{r}=.273, p<.05)$ and with community bonds $(\mathrm{r}=.441, p<$ $.01)$. The competence subscale showed a weak positive relationship with community bonds $(\mathrm{r}=.369, p<.01)$. The relatedness sub-scale showed a moderate positive relationship with community bonds $(\mathrm{r}=.589, p<.01)$ and pro-social support $(\mathrm{r}=$ $.480, p<.01)$. Community bonds and pro-social support showed a moderate negative relationship $(\mathrm{r}=-.326, p<.05)$. Overall, meaningful employment seemed to cluster with perceived level of support, particularly from the prison community. In contrast, relationship attachment did not seem to meaningfully link to other social factors. 
Participants appeared, to an extent, to have greater bonds to either the prison community or pro-social others in their support network.

\section{Subjective factors}

Three of the subjective factors (pro-social attitudes, agency and resilience) showed significant moderate positive relationships with each other. Age was not significantly related to any of the other subjective factors.

\section{Relationships between social and subjective factors}

Oddly, agency showed a weak positive relationship with the autonomy subscale of meaningful employment $(\mathrm{r}=.309, p<.05)$ and the relatedness subscale $(\mathrm{r}=.321, p$ $<.05)$ but no relationship to the competency subscale $(\mathrm{r}=.229, p>.05)$, despite it being the most conceptually similar construct. Resilience showed a weak positive relationship to pro-social support $(\mathrm{r}=.354, p<.01)$ and to all of the meaningful employment subscales. Age showed a weak negative relationship to the autonomy ( $\mathrm{r}$ $=-.422, p<.01)$ and competence $(r=-.392, p<.05)$ subscales of meaningful employment. Relationship attachment and community bonds were unrelated to any subjective factors. Similarly, pro-social attitudes were unrelated to any social factors. Overall, there appeared to be some bi-directional relationships between subjective and social factors, with the main overlap being between meaningful employment and subjective factors and some interaction between pro-social support and resilience. However, to an extent it appeared that prisoners had strong community bonds without an accompanying 'internal shift', or conversely held pro-social attitudes without having significant social capital.

\section{Differences between persisters and desisters}

In order to address the main hypotheses, persisters and desisters were compared on the eight continuous dependent variables. This was done using t-tests with a Bonferroni correction to control the Type I error rate. The acceptable significance rate was set at $p<.006$. The two groups were also compared on the two categorical variables that were recorded (presence or absence of employment and a long-term relationship), using a chi-square test of significance. Table 2 shows the mean scores 
for persisters and desisters on each of the dependent variables and effect sizes for each variable. A higher score indicates greater presence of the variable in question.

[Table 2 about here]

All differences between groups were in the expected direction (desisters scored higher), with the exception of age. Desisters ( $M=24.5$ years) were younger than persisters ( $M=27.6$ years). The only significant differences between groups were in their scores for pro-social attitudes $(t(56)=-3.09, p<.006, d=.87)$, agency $(t(56)$ $=-3.98, p<.006, d=1.12)$ and resilience $(t(56)=-3.14, p<.006, d=.89)$. Although other variables were not significantly different between groups, some still showed moderate effect sizes for desistance. These were age $(d=-.54)$, autonomy ( $d$ $=.58)$ and relatedness $(d=.69)$ scores for meaningful employment. All other variables showed small effect sizes (see Table 2).

\section{Predicting desistance}

A binary logistic regression analysis was conducted to assess the relative importance of the six variables that showed moderate-to-large effect sizes in the previous analysis (age, autonomy in employment, relatedness in employment, pro-social attitudes, agency and resilience). Those variables with moderate-to-large effect sizes that did not reach significance were still included as the power analysis suggested that some differences may not be detected with the number of participants in the study. Age was entered as an interaction term for each of the other predictors and was categorised using a median split. All variables were entered using a stepwise backward deletion method so that the model could be built incrementally and provide more insight into the contribution of different variables than a simultaneous method would. A backward deletion procedure was chosen to avoid suppression effects (Field, 2009). The results of the final model are presented in Table 3 below.

[Table 3 about here] 
The final model was statistically significant $(\chi 2(5, \mathrm{n}=46)=29.96, p<.001)$, indicating that the combination of variables could differentiate desisters from persisters. However, the model was better at classifying desisters (92.9\%) than persisters $(72.2 \%)$, and overall $84.8 \%$ of individuals were correctly classified. The combined multivariate model accounted for $63 \%$ of the variance in violence status (Nagelkirk R2). Table 3 shows that agency was the only single variable that predicted group membership independently of all others and interaction terms. For each one point increase in agency, the likelihood of an individual being a desister increased by $14 \%$. Although retained in the final model, the interactions between age and resilience, and age and relatedness were not significant independent predictors of violence status. The significant interactions obtained for autonomy and agency were explored by conducting individual logistic regression analyses separately for the two age groups. It was found that in the case of autonomy at work, the effect was stronger for the older age-group $(\mathrm{OR}=1.47,95 \% \mathrm{CI}=.97-2.26, p=.07)$ than the younger age group $(\mathrm{OR}=1.05,95 \% \mathrm{CI}=.86-1.29, p=.63)$. However, in both instances this association was not statistically robust. In the case of agency, it was found that the effect was stronger for the younger $(\mathrm{OR}=1.14,1.03-1.25, p=.01)$ than the older age group $(\mathrm{OR}=1.07,95 \% \mathrm{CI}=.99-1.15, p=.07)$. In this instance for each one unit increase in agency reported by the younger offenders, the likelihood of desistance increased by $14 \%$.

\section{Discussion}

This was the first study to examine the factors associated with desistance from prison violence. Its aim was to explore whether factors associated with desistance in community samples can usefully distinguish persisters and desisters from prison violence, and which hold the most predictive power. As expected, desisters were characterised by greater pro-social attitudes, higher levels of agency and higher resilience. There was also some evidence that younger age and feelings of autonomy and relatedness in the workplace were relevant to desistance, though these relationships did not reach significance. The only factor which independently predicted desistance was agency, however the model incorporating these six factors correctly classified $92.9 \%$ of desisters, which suggests that they all hold some relevance. In addition, although community bonds and pro-social support were not directly related to desistance, they were related to positive feelings about 
employment, which in turn was related to resilience, and resilience to desistance. The overall picture suggests that a desister from prison violence is a younger man who experiences a sense of belonging which is often drawn from his workplace, has developed a belief that violence is unacceptable, feels able to take control of his choices and has the skills to cope with adversity. These skills are partly related to the amount of support he receives.

This picture supports some of the theoretically driven suggestions from the existing literature. The link between employment and positive social bonds supports McNeill and Weaver (2015)'s assertion that it is positive social relations that drive desistance, and this seems to be the case to a certain extent regarding prison violence. However the stronger effect of subjective factors suggests that the effect of employment may be limited, possibly due to the varying social norms between workplaces (Crewe et al. 2014) and the continued presence of anti-social opportunities despite employment. This means that employment is not disrupting routine anti-social activities, which Sampson and Laub (2003) assert is one of the means by which employment drives desistance in the community.

The effect of subjective factors (except age) supports findings by Maruna (2001) and LeBel et al. (2008) that an internal shift is crucial, and precedes choices to maximize available social capital. The relative lack of significance of social factors suggests that an internal shift is even more important in prison. This makes sense in the light of Farrall and Calverley (2006)'s findings that a confident outlook is needed in order to overcome obstacles. Prison culture presents significant obstacles to desistance and these findings suggest that only those with the highest commitment to non-violence and confidence in their coping abilities will desist successfully. The independent predictive effect of agency suggests that perception of choice is the most important factor, which is supported by Maruna (2001)'s finding that an overinflated sense of optimism characterises desisters. The lack of a predictive effect of pro-social attitudes may be explained by Crewe et al. (2014)'s findings on the assumption of multiple identities within the prison environment. Prosocial attitudes may indicate a commitment to desistance but not necessarily be translated into behavior if prisoners believe they must still adopt a violent identity under certain conditions.

The lack of influence of some factors followed some of the patterns suggested by existing theory. The presence of a good quality intimate relationship 
was not related to desistance, and this is likely to be because it is not present enough to act as a means of informal social control (Sampson and Laub 2003). Previous work suggests that an identity as a family man influences desistance (Maruna 2001; LeBel et al. 2008). In this study this identity was not directly investigated, however there was no relationship between intimate relationships and pro-social attitudes, which suggests that if such an identity was present, it was not directly feeding in to a non-violent identity. Community bonds was also not directly related to desistance, and this is supported by the suggestion that it is the prevailing norms which define that community (in this case pro-violent norms) that will inhibit or facilitate behavior (McNeill and Weaver 2015). This study did not differentiate different areas of the prison community so it may be that bonds to both pro- and anti-social communities were subsumed under one measure, which led to it showing no effect. The indirect link to positive employment suggests that community bonds in prison may exert some effect on desistance when such bonds are to a pro-social community area. Another potential explanation for the lack of observed effects is that the model only correctly classified $72.2 \%$ of persisters, which suggests that there may be some unique variables driving persistence in prison violence that the study did not capture.

The association between agency, desistance and younger age contrasts with findings from the community, where increasing age has been associated with increased feelings of agency and increased desistance (Giordano et al. 2002; Maruna 2001). Giordano et al. reason that this is because age increases the likelihood of exposure to social factors and life experiences that might encourage more 'agentic' thinking (e.g. birth of a child), and also that agentic thinking is simply a product of maturation and increasing ability for intentional and reflective actions. As violence in prison is a behaviour limited to time in a custodial setting, it may be that prisonspecific factors affect the development of a sense of agency (such as positive employment experiences and resilience) and that younger prisoners gain more exposure to these than they would in a community setting, which means they are more effective. It may also be that the desisters and persisters were differentiated by other confounding variables which were not measured. For example, being incarcerated and of an older age may be representative of a lengthier sentence for a more severe offences or a lengthier offending history, both of which increase preexisting risk level. If this were true then persistence may be an artefact of higher risk level rather than age per se. 


\section{Strengths and limitations}

There are several strengths and limitations that should be taken into account when interpreting the results of the study. Its main strength is that it has addressed gaps in the literature highlighted by others. Farrington (2007) noted that desistance researchers needed to expand their work to other locations, and Walker, Bowen and Brown (2013) highlighted a need for further research into desistance from violence. This is the first study to consider desistance from prison violence and has therefore added to knowledge about the desistance process in secure conditions and for violent offences. It has also considered the differential influences of social and subjective factors and how these combine, which has been a growing demand (Bottoms et al., 2004; Giordano et al., 2002; LeBel et al., 2008). Methodologically the study has addressed some concerns raised by Farrington (2007). Desistance was classified based on both official and self-report measures, which increases the possibility that it is true desisters being studied. Desistance was given a clear operational definition which allows more effective comparison with other studies of desistance.

The main limitation of the study was its focus on breadth rather than depth. It considered a wide range of variables which meant limited power to detect smaller effects, especially given the relatively small sample size (63) for the number of variables studied. This may explain why some variables associated with desistance in community showed no effect. Another limitation is that only factors associated with community desistance were studied, which means factors unique to the prison environment may have been missed. Risk related information was not measured in order to preserve anonymity. Pre-existing risk level could potentially explain differences between desisters and persisters and could also give valuable insight into which factors predict desistance in high risk offenders who are often the most challenging to manage in secure conditions (Belfrage, Fransson and Strand, 2004). Three further limitations are the short follow up period (12 months), not measuring length of desistance and problems with self-report, such as social desirability.

\section{Recommendations}

As this is the first study of its kind, further studies of desistance in custodial conditions would be useful in order to see if findings are replicated. Further studies 
could build upon this one by using a larger sample size, collecting more risk related information, measuring variables unique to the prison environment, using a longer follow-up period, collecting data prospectively and including qualitative data. One of the proposed benefits of applying a desistance-based approach to prison violence was that it may suggest ways to reduce violence in a more cost-effective manner. The findings suggest that creating an environment which promotes agency and prosocial bonds could be effective. Recent investment has been made in creating such environments in prison through a joint initiative from the Ministry of Justice and Department of Health called Psychologically Informed Planned Environments (or PIPEs). The principles of PIPE units include encouraging positive community relationships and promoting autonomy (DoH and MoJ, 2012). They are therefore promoting the factors which this study has found to have the strongest association with desistance from custodial violence. The findings from this study lend some weight to the idea that continued investment in PIPEs may have a positive impact on prison violence.

\section{Conclusions}

Overall, the study has shown that desistance from prison violence does occur and that it is possible to identify factors associated with it. These factors are both subjective and social, which supports recent thinking about it is the bi-directional interaction of different factors which influences desistance. However subjective factors appear to assume a particular importance in prison. Agency, a pro-social stance, and support are all things identified as important for desistance in previous work (Farrall and Caverley 2006; Kazemian and Farrington, 2010; Maruna, 2001), and although the particular sources from which these things are derived may differ between custody and community, the findings suggest that enhancing these factors by whatever means a prison has available could help to reduce custodial violence.

\section{References}

Belfrage, H., Fransson, G., \& Strand, S. (2004). Management of violent behaviour in the correctional system using qualified risk assessments. Legal and Criminological Psychology, 9, 11-22. 
Bennett, A. L. (2014). Service users' initial hopes, expectations and experiences of a high security psychologically informed planned environment (PIPE). The Journal of Forensic Practice, 16, 216-227.

Bottoms, A. \& Shapland, J. (2011). Steps towards desistance among male young adult recidivists. In S. Farrall, M. Hough, S. Maruna \& R. Sparks (Eds.), Escape routes: Contemporary perspectives on life after punishment (pp. $43-$ 80). Oxfordshire: Routledge.

Bottoms, A., Shapland, J., Costello, A., Holmes, D., \& Muir, G. (2004). Towards desistance: Theoretical underpinnings for an empirical study. Howard Journal of Criminal Justice, 43, 368-389. doi:10.1111/j.14682311.2004.00336.x

Brien, M., Forest, J., Mageau, G. A., Boudrias, J., Desrumaux, P., Brunet, L., \& Morin, E. M. (2012). The Basic Psychological Needs at Work scale: Measurement invariance between Canada and France. Applied Psychology: Health \& Well-being, 4, 167-187. doi:10.1111/j.1758-0854.2012.01067.x

Burnett, R. (2004). To re-offend or not re-offend? The ambivalence of convicted property offenders. In S. Maruna \& R. Immarigeon (Eds.), After crime and punishment: Pathways to offender reintegration (pp. 152 - 180). Cullompton: Willan

Campbell-Sills, L., \& Stein, M. B. (2007). Psychometric analysis and refinement of the Connor-Davidson Resilience Scale (CD-RISC): Validation of a 10-item measure of resilience. Journal of Traumatic Stress, 20, 1019-1028. doi:10.1002/jts.20271

Cheliotis, L. K. (2014). Our violence and theirs: Comparing prison realities. South Atlantic Quarterly, 113, 443-446. doi:10.1215/00382876-2692137

Chung, I., Hill, K. G., Hawkins, J. D., Gilchrist, L. D., \& Nagin, D. S. (2002). Childhood predictors of offense trajectories. Journal of Research in Crime and Delinquency, 39, 60-90.

Clinkinbeard, S. S., \& Murray, C. I. (2012). Perceived support, belonging, and possible selves: Strategies among incarcerated juvenile offenders. Journal of Applied Social Psychology, 42, 1218-1240. doi:10.1111/j.15591816.2011.00884.x

Coates, E. E., Phares, V., \& Dedrick, R. F. (2013). Psychometric properties of the Connor-Davidson Resilience Scale 10 among low-income, African American men. Psychological Assessment, 25, 1349-1354. doi:10.1037/a0033434 
Crewe, B., Warr, J., Bennett, P., \& Smith, A. (2014). The emotional geography of prison life. Theoretical Criminology, 18, 56-74. doi:10.1177/1362480613497778

Department of Health and Ministry of Justice (2012). A Guide to Psychologically Informed Planned Environments (PIPEs). London: Department of Health and Ministry of Justice.

Douglas, K. S., Hart, S. D., Webster, C. D. \& Belfrage, H. (2013). HCR-20: Assessing risk for violence. Version 3 manual.

Farrall, S. \& Calverley, A. (2006). Understanding desistance from crime: Theoretical directions in resettlement and rehabilitation. Berkshire: Open University Press.

Farrington, D. P. (2007). Advancing knowledge about desistance. Journal of Contemporary Criminal Justice, 23, 125-134.

Farrington, D. \& West, D. (1995). Effects of marriage, separation and children on offending in adult males. In Z. Blau \& J. Hagan (Eds.), Current perspectives on aging and the life-cycle (pp. 249-281). Greenwich CT: JAI Press.

Fergusson, D. M., Lynskey, M. T., \& Horwood, L. J. (1996). Factors associated with continuity and changes in disruptive behavior patterns between childhood and adolescence. Journal of Abnormal Child Psychology, 24, 533553.

Field, A. (2009). Discovering statistics with SPSS (3rd ed.). London: Sage.

Frude, N., Honess, T. and Maguire, M. (2013). CRIME-PICS II manual. M\&A Research.

Giordano, P. C., Cernkovich, S. A., \& Rudolph, J. L. (2002). Gender, crime, and desistance: Toward a theory of cognitive transformation. American Journal of Sociology, 107, 990-1064.

Haggård, U., Gumpert, C. H., \& Grann, M. (2001). Against all odds: A qualitative follow-up study of high risk violent offenders who were not reconvicted. Journal of Interpersonal Violence, 16, 1048-1065.

Hawkins, J., Herrenkohl, T., Farrington, D., Brewer, D., Catalano, R. \& Harachi, T. (1998). A review of the predictors of youth violence. In R. Loeber \& D. Farrington (Eds.), Serious and violent juvenile offenders: Risk factors and successful interventions (pp. 106 - 146). Thousand Oaks CA: Sage. 
Herrenkohl, T. I., Hill, K. G., Chung, I., Guo, J., Abbott, R. D., \& Hawkins, J. D. (2003). Protective factors against serious violent behavior in adolescence: A prospective study of aggressive children. Social Work Research, 27, 179-191.

Herrenkohl, T. I., Huang, B., Kosterman, R., Hawkins, J. D., Catalano, R. F., \& Smith, B. H. (2001). A comparison of social development processes leading to violent behavior in late adolescence for childhood initiators and adolescent initiators of violence. Journal of Research in Crime and Delinquency, 38, 4563.

Herrero, J., \& Gracia, E. (2007). Measuring perceived community support: Factorial structure, longitudinal invariance, and predictive validity of the PCSQ (Perceived Community Support Questionnaire). Journal of Community Psychology, 35, 197-217.

Homel, R. and Thompson, C. (2005) 'Causes and prevention of violence in prisons', S. O'Toole \& S. Eyland (Eds.), Corrections Criminology (pp. 101-108). Sydney: Hawkins Press.

Horney, J., Osgood, D. W., \& Marshall, I. H. (1995). Criminal careers in the shortterm: Intra-individual variability in crime and its relation to local life circumstances. American Sociological Review, 60, 655-673.

House of Commons Committee of Public Accounts. (2013). Restructuring the National Offender Management Service (Thirty-fifth report of session 201213). London: The Stationery Office.

Kazemian, L. \& Farrington, D. (2010). The developmental evidence base: Desistance. In G. Towl \& D. Crighton (Eds.), Forensic Psychology (pp. 133147). New Jersey: Wiley-Blackwell.

Knight, B., Osborn, S. \& West, D. (1977). Early marriage and criminal tendencies in males. British Journal of Criminology, 17, 348-360.

Laub, J. H., Nagin, D. S., \& Sampson, R. J. (1998). Trajectories of change in criminal offending: Good marriages and the desistance process. American Sociological Review, 63, 225-238.

Laub, J. H., \& Sampson, R. J. (1993). Turning points in the life course: Why change matters to the study of crime. Criminology, 31, 301-325.

LeBel, T. P., Burnett, R., Maruna, S., \& Bushway, S. (2008). The 'chicken and egg' of subjective and social factors in desistance from crime. European Journal of Criminology, 5, 131-159.

Lloyd, C. D., \& Serin, R. C. (2012). Agency and outcome expectancies for crime 
desistance: Measuring offenders' personal beliefs about change. Psychology, Crime \& Law, 18, 543-565.

Loeber, R., Farrington, D. P., Stouthamer-Loeber, M., Moffitt, T. E., \& Caspi, A. (1998). The development of male offending: Key findings from the first decade of the Pittsburgh Youth Study. Studies on Crime \& Crime Prevention, 7, 141-171.

MacDonald, R., Webster, C., Shildrick, T. \& Simpson, M. (2011). Paths of exclusion, inclusion and desistance: Understanding marginalised young people's criminal careers. In S. Farrall, M. Hough, S. Maruna \& R. Sparks (Eds.), Escape routes: Contemporary perspectives on life after punishment (pp. 134-157). Oxfordshire: Routledge.

Maruna, S. (2001). Making good: How ex-convicts reform and rebuild their lives. Washington, DC: American Psychological Association. doi:10.1037/10430000

Maume, M. O., Ousey, G. C., \& Beaver, K. (2005). Cutting the grass: A reexamination of the link between marital attachment, delinquent peers and desistance from marijuana use. Journal of Quantitative Criminology, 21, 2753. doi:10.1007/s10940-004-1786-3

McCorkle, R. C., Miethe, T. D., \& Drass, K. A. (1995). The roots of prison violence: A test of the deprivation, management, and 'not-so-total' institution models. Crime \& Delinquency, 41, 317-331.

McNeill, F., \& Weaver, B. (2015). Lifelines: Desistance, social relations and reciprocity. Criminal Justice and Behavior, 42, 95-107.

Ministry of Justice. (2016). Safety in custody statistics bulletin England and Wales. Deaths in prison custody to June 2016. Assaults and self-harm to March 2016. London: Ministry of Justice.

National Offender Management Service (2012). PSI 64/2011: Management of prisoners at risk of harm to self, to others and from others. London: Ministry of Justice.

National Offender Management Service. (2013). Business plan 2013 - 2014. London: Ministry of Justice.

Notario-Pacheco, B., Martínez-Vizcaíno, V., Trillo-Calvo, E., Cruz Pérez-Yus, M., Serrano-Parra, D., \& García-Campayo, J. (2014). Validity and reliability of the Spanish version of the 10-item CD-RISC in patients with fibromyalgia. Health and Quality of Life Outcomes, 12, 1-9. doi:10.1186/1477-7525-12-14 
Rennie, C. E., \& Dolan, M. C. (2010). The significance of protective factors in the assessment of risk. Criminal Behaviour and Mental Health, 20, 8-22.

Rhodes, W. (1989). The criminal career: Estimates of the duration and frequency of crime commission. Journal of Quantitative Criminology, 5, 3-32.

Sampson,R. J., \& Laub, J. H. (2003). Life-course desisters? trajectories of crime among delinquent boys followed to age 70. Criminology, 41, 555-592.

Serin, R. C., \& Lloyd, C. D. (2009). Examining the process of offender change: The transition to crime desistance. Psychology, Crime \& Law, 15, 347-364. doi:10.1080/10683160802261078

Shover, N. (1996). Great pretenders: Pursuits and careers of persistent thieves. Boulder CO: Westview.

Shover, N., \& Thompson, C. Y. (1992). Age, differential expectations, and crime desistance. Criminology, 30, 89-104.

Stouthamer-Loeber, M., Wei, E., Loeber, R., \& Masten, A. S. (2004). Desistance from persistent serious delinquency in the transition to adulthood. Development and Psychopathology, 16, 897-918.

Toch, H. (1998). Hypermasculinity and prison violence. In L. H. Bowker (Ed.), Research on men and masculinities: Masculinities and violence (pp. 168178). Thousand Oaks, CA, US: Sage Publications.

Toch, H. (2008). Cumulative default: The cost of disruptive prison careers. Criminal Justice and Behavior, 35, 943-955.

Toch, H. (2010). "I am not now who I used to be then": Risk assessment and the maturation of long-term prison inmates. Prison Journal, 90, 4-11. doi:10.1177/0032885509356408

Turley, C., Payne, C. and Webster, S. (2013). Enabling features of Psychologically Informed Planned Environments. London: Ministry of Justice.

Uggen, C. (2000). Work as a turning point in the life course of criminals: A duration model of age, employment, and recidivism. American Sociological Review, 65, 529-546.

Ullrich, S., \& Coid, J. (2011). Protective factors for violence among released prisoners-Effects over time and interactions with static risk. Journal of Consulting and Clinical Psychology, 79, 381-390. doi:10.1037/a0023613

van Domburgh, L., Loeber, R., Bezemer, D., Stallings, R., \& Stouthamer-Loeber, M. 
(2009). Childhood predictors of desistance and level of persistence in offending in early onset offenders. Journal of Abnormal Child Psychology, 37, 967-980.

Walker, K., Bowen, E., \& Brown, S. (2013). Psychological and criminological factors associated with desistance from violence: A review of the literature. Aggression and Violent Behavior, 18, 286-299.

Walrath, C. (2001). Evaluation of an inmate-run alternatives to violence project: The impact of inmate-to-inmate intervention. Journal of Interpersonal Violence, $16,697-711$.

Wang, L., Shi, Z., Zhang, Y., \& Zhang, Z. (2010). Psychometric properties of the 10-item Connor-Davidson Resilience Scale in Chinese earthquake victims. Psychiatry \& Clinical Neurosciences, 64, 499-504. doi:10.1111/j.14401819.2010.02130.x

Warr, M. (1993). Parents, peers, and delinquency. Social Forces, 72, 247-264.

Werner, E. E., \& Smith, R. S. (1992). Overcoming the odds: High risk children from birth to adulthood. Ithaca, NY: Cornell University Press.

Wright, J. P., \& Cullen, F. T. (2004). Employment, peers, and life-course transitions. JQ: Justice Quarterly, 21,183-205. 


\section{Appendix I: Full description of outcome measures used}

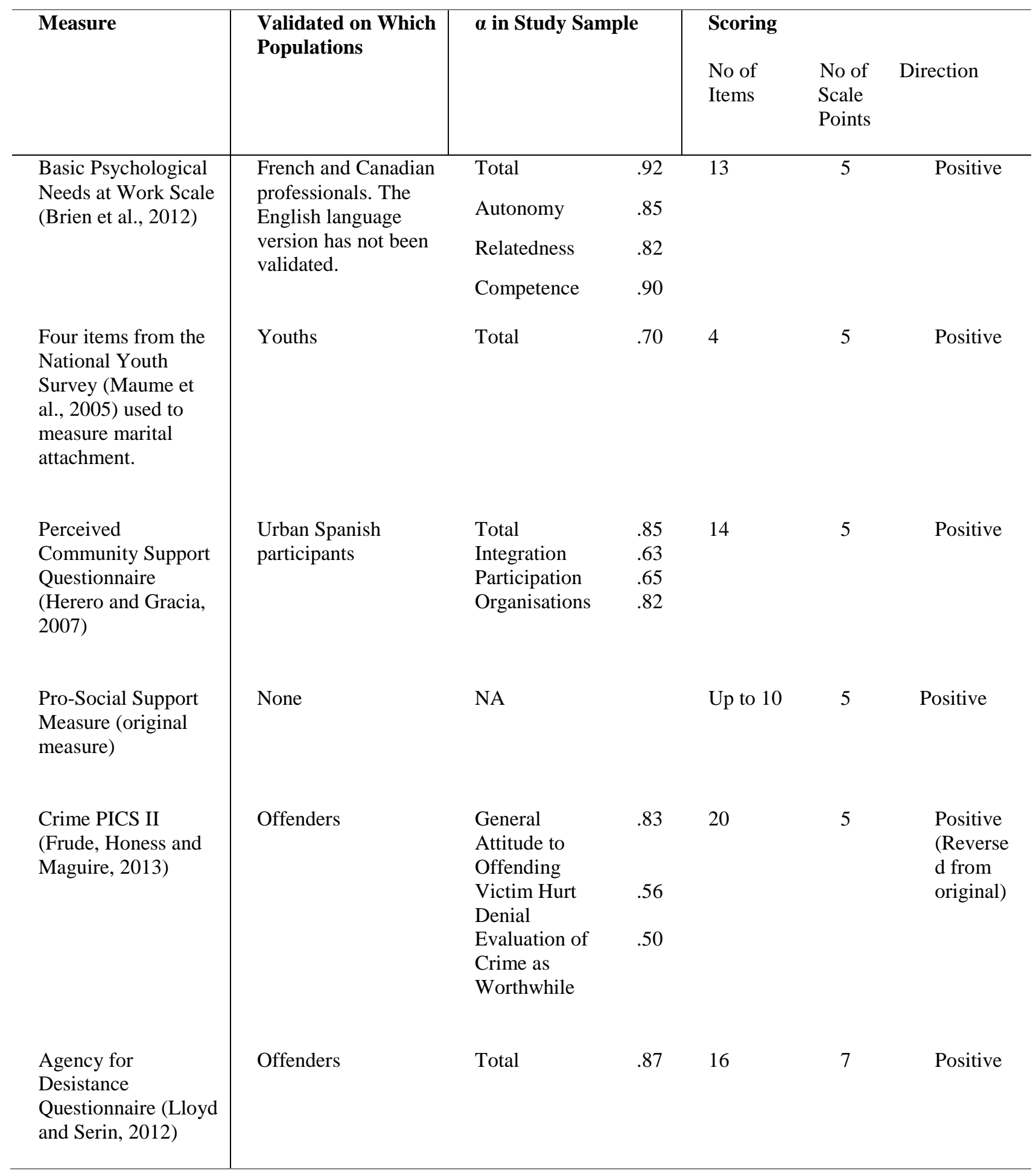


Connor-Davidson

Resilience Scale - 10

Item Version

(Campbell-Sills and

Stein, 2007)
Various cultural

samples (e.g. Coates,

Phares and Dedrick,

2013; Notario-

Pacheco et al., 2014;

Wang, Sji, Zang and

Zang, 2010). $\begin{array}{lllll}\text { Total } & 90 & 10 & 5 & \text { Positive }\end{array}$ 
Table 1: Correlation matrix for the continuous dependent variables

\begin{tabular}{|c|c|c|c|c|c|c|c|c|c|}
\hline Factor & $\begin{array}{l}\text { BPNW }^{\mathrm{a}} \\
\text { Autonomy }\end{array}$ & $\begin{array}{l}\mathrm{BPNW}^{\mathrm{a}} \\
\text { Competence }\end{array}$ & $\begin{array}{l}\mathrm{BPNW}^{\mathrm{a}} \\
\text { Relatedness }\end{array}$ & $\begin{array}{l}\text { Relationship } \\
\text { Attachment }\end{array}$ & $\begin{array}{l}\text { Community } \\
\text { Bonds }\end{array}$ & $\begin{array}{l}\text { Pro-Social } \\
\text { Support }\end{array}$ & $\begin{array}{l}\text { Pro-Social } \\
\text { Attitudes }\end{array}$ & Agency & Resilience \\
\hline Age & $-.422 * *$ & $-.392 * *$ & -.179 & .027 & -.074 & .189 & .239 & .007 & .047 \\
\hline $\begin{array}{l}\text { BPNW }^{\mathrm{a}} \\
\text { Autonomy }\end{array}$ & ----- & $.752 * *$ & $.586^{* *}$ & $.273 *$ & $.441 * *$ & .227 & -.036 & $.309 *$ & $.299 *$ \\
\hline $\begin{array}{l}\mathrm{BPNW}^{\mathrm{a}} \\
\text { Competence }\end{array}$ & & ----- & $.563^{* *}$ & .164 & $.369 * *$ & .032 & -.051 & .229 & $.332 *$ \\
\hline $\begin{array}{l}\text { BPNW }^{\mathrm{a}} \\
\text { Relatedness }\end{array}$ & & & ----- & .259 & $.589 * *$ & $.480 * *$ & .151 & $.321 *$ & $.366^{* *}$ \\
\hline $\begin{array}{l}\text { Relationship } \\
\text { Attachment }\end{array}$ & & & & ----- & .089 & .180 & .138 & .018 & .052 \\
\hline $\begin{array}{l}\text { Community } \\
\text { Bonds }\end{array}$ & & & & & ----- & $.326 * *$ & .055 & .161 & .130 \\
\hline $\begin{array}{l}\text { Pro-Social } \\
\text { Support }\end{array}$ & & & & & & ----- & .086 & .233 & $.354 * *$ \\
\hline $\begin{array}{l}\text { Pro-Social } \\
\text { Attitudes }\end{array}$ & & & & & & & ----- & $.513^{* *}$ & $.437 * *$ \\
\hline Agency & & & & & & & & ----- & $.449 * *$ \\
\hline
\end{tabular}

$*=\mathrm{p}<.05 \quad * *=\mathrm{p}<.01 \quad{ }^{\mathrm{a}}$ Basic Psychological Needs at Work Scale (used to measure dimensions of meaningful employment) 
Table 2: Percentages and mean scores for persisters and desisters on each factor measured

\begin{tabular}{|c|c|c|c|}
\hline Variable (Max. Score) & Persisters (SD) & Desisters (SD) & Effect Size (Type) \\
\hline Employed & $84.2 \%$ & $95 \%$ & $.15(\varphi)$ \\
\hline In an Intimate Relationship & $31.3 \%$ & $35.5 \%$ & $.26(\varphi)$ \\
\hline Age (years) & $27.6(6.8)$ & $24.5(2.6)$ & $0.54(\mathrm{~d})$ \\
\hline BPNW Autonomy (24) & $17.7(4.9)$ & $20.3(3.8)$ & $0.58(\mathrm{~d})$ \\
\hline BPNW Competence (24) & $19.8(3.9)$ & $20.9(2.6)$ & $0.30(\mathrm{~d})$ \\
\hline BPNW Relatedness (24) & $15.2(5.7)$ & $18.6(3.5)$ & $0.69(d)$ \\
\hline Relationship Attachment (20) & $4.1(7.4)$ & $4.1(7.6)$ & $0.01(\mathrm{~d})$ \\
\hline $\begin{array}{l}\text { Relationship Attachment (excluding those who were not in a } \\
\text { relationship) }\end{array}$ & $16.7(3.4)$ & $17.2(3.0)$ & $0.16(d)$ \\
\hline Community Bonds (70) & $45.1(8.7)$ & $48.3(9.5)$ & $0.36(d)$ \\
\hline Pro-Social Support (50) & $15.5(16.6)$ & $19.2(17.1)$ & $0.26(\mathrm{~d})$ \\
\hline $\begin{array}{l}\text { Pro-Social Support (excluding those who reported no } \\
\text { support) }\end{array}$ & $24.2(14.9)$ & $26.9(14.0)$ & $0.20(\mathrm{~d})$ \\
\hline Pro-Social Attitudes (95) & $70.7(8.5)^{*}$ & $78.2(9.3)^{*}$ & $0.87(\mathrm{~d})$ \\
\hline Agency (112) & $75.0(14.5)^{*}$ & $91.1(14.8)^{*}$ & $1.12(\mathrm{~d})$ \\
\hline Resilience & $35.6(8.6)^{*}$ & $42.7(7.2)^{*}$ & $0.89(\mathrm{~d})$ \\
\hline
\end{tabular}

$* \mathrm{p}<.05$

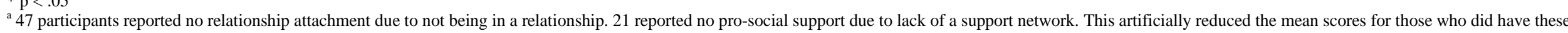
things present. Therefore, mean scores that exclude those who scored 0 are also reported. 
Table 3: Final multivariate logistic regression model $(N=46)$

\begin{tabular}{lccccc}
\hline Variable & Beta & S.E. & Wald & OR (95\% CI) & $\mathrm{p}$ \\
\hline Age x Autonomy & .80 & .37 & 4.61 & $2.13(1.07-4.58)$ & .032 \\
Age x Relatedness & -.56 & .30 & 3.58 & $.57(.32-1.02)$ & .058 \\
Agency & .13 & .04 & 8.72 & $1.14(1.04-1.24)$ & .003 \\
Age x Agency & -.18 & .09 & 4.12 & $.83(.70-.99)$ & .042 \\
Age x Resilience & .19 & .12 & 2.40 & $1.20(.95-1.52)$ & .122 \\
\hline
\end{tabular}

